Stone levitated by sound could become a flying chariot moving along the line of a certain magnetic intensity, whose course was marked out on the ground by alignments of stones and earthworks, linked by raised causeways and rides through the forest. With the Earth's magnetic [sic] field regulated and the streams that run through it diverted to conform to straight lines, the stone craft and its navigator could float from centre to centre, picking their way through a canal network of alternating currents and choosing the level of intensity to which their vibrations were attuned...'

Geophysicists also please note! Yours faithfully, P. LANCASTER BROWN

Beaconsfield, Bucks

\section{Closely observed trains}

SIR,-The facile comment under the photograph on page six of your journal of the 6th of September, prompts me to raise a few points with regard to the present state of magnetic suspension technology in this country and abroad.

How good at speed? Your correspondent gives the answer herself on page seven. The 45 mile track being constructed in Germany is for a high speed system using controlled electromagnets. The proposed speeds are $500 \mathrm{~km} / \mathrm{h}$. Krauss Maffei have no problems that they cannot overcome on eddy currents up to 400-450 m.p.h. Our own tests confirm the Krauss Maffei measurements made in 1972 when they ran their vehicle at over 150 k.p.h. Nobody in their right minds and connected with the d.c. electromagnet suspension technology would see any problems at speeds as low as $50 \mathrm{~m}$.p.h. The problems at Toronto are those of linear induction motors and the inverter drive for them. It is also worth noting that work on the French Aerotrain has come to a halt and discussions have taken place between the French and German authorities on a joint programme of development of the controlled electromagnet systems, for intercity and transeuropean network. So much for the misplaced Sussex claims.

There is in my opinion, an obsession with high speed and ground transport which in turn leads to a complete blinding of the technical problems (never mind the social problems) of high speed vehicles. Guidance of such vehicles is not a matter of showing that 201b aluminium plates or one ton vehicles in laboratories have stability. The turning moments on a 30 ton, 100 passenger vehicle are of the order of 40000 N.M. The aerodynamic drag alone is more than $2000 \mathrm{~kW}$ and therefore that is the size of the required linear motor. (The suspension power using d.c. electromagnets is $30 \mathrm{~kW}$ ).

No-one claims to have solved the problem of collecting this sort of power at 300 m.p.h. from what your correspondent calls "normal a.c. mains". It is a little bit more difficult than plugging a shaver into a socket. If two of these trains cross each other this will impose an impulse load of more than four MegaWatts on the area generating board. Is the generating board going to be happy about this happening at three min. intervals? Are the high speed vehicles to run from $\mathbf{A}$ to B only or are they intended to change routes at speed? If yes, has some consideration been given to each proposal including the tracked hovercraft? The cost apart, these are some of the more formidable problems of high speed transportation vehicles. There are a few mundane ones like response times of the guidance systems, an accurate estimate of propulsion and suspension powers (no-one gets this as a bonus, as has been claimed), dependence of guidance and suspension forces on speed, power factors and efficiencies of the proposed equipment to name a few.

My team and I have lived with these problems for the last five years and are in a position to offer experimental evidence on suspension, guidance and propulsion aspects (including eddy current drag). We do not claim to have solved the world's transportation problems or to offer the ultimate system. The Germans have been developing their d.c. electromagnet systems for the last three years and are going ahead with the same technology for high speed application. The Japanese on the other hand have run into serious problems of guidance on their cryogenic system. We could investigate our system on the Brighton seafront to find out (a) whether it is possible to implement it in our cities and (b) whether a high speed system is feasible. Alternatively, we could always buy the finished article from Germany say, in 1985 or 1990.

The choice of Brighton seafront is not so gimicky as it appears. Environmentally it is one of the toughest locations one could choose with corrosion and high winds presenting a severe test of any installation.

Whether Professor Laithwaite's magnetic river system is superior to all others can only be judged when he produces enough technical data and hardware to justify his claims. Even if it is, his problems will only then begin. A high speed transport system cannot be developed on a domestic market. A transeuropean system is likely to be German-French dictated. Perhaps Sussex claims are not all that misplaced! Yours faithfully, B. V. JAYAWANT

University of Sussex.

Applied Science Laboratory,

Brighton
Time for a change?

Sir,-In Nature, Vol. 250, August 30, 1974 was published a paper by Charles E. Chaffey on a time-measuring system based on SI units. Obscurantism for its own sake is admirably displayed in this paper. The time-system postulated is unintelligible, having no frame of reference, and being unrelated to realitydays, lunar months and years, which exist on this planet in the absence of all arbitrary measurement.

The author states that his aim is "the elimination of timers graduated in diverse units", presumably without regard to convenience or intelligibility. The SI second, though defined differently, is still based upon day length divided by $24 \times 60 \times 60$, therefore is irrational in terms of the decimal system (the division of the clock dial into 12 or 24 is rationally related to the geometry of the circle). Surely, if a so-called 'rational' system is to be adopted by scientists, then it should be the metric clock and the French Revolutionary Calendar (now being the last month of 182).

Incidentally, what is the starting point of C. Chaffey's calendar? The Christian era? Surely not. Why not Sir Isaac Newton's birthday? This would have the merit as being the same day as Christmas, and would remind all scientists of this great alchemist/ astrologer/theologian who founded our new religion.

$$
\begin{aligned}
& \text { Yours faithfully, } \\
& \text { NrgeL PENNICK }
\end{aligned}
$$

Trumpington,

Cambs.

\section{Group papers}

SIR,-Alan Mackay's proposal (Nature $250,698 ; 1974)$ that papers should be published in the name of the research groups rather than of the individuals, deserves serious consideration in spite of his outdated references (to St. Matthew and Church of England Articles). This procedure has in fact been encouraged in China. The prime purpose of scientific communication is definitely better served by an improved standard, and decreased number, of publications (have you not read any recent issue of J. Irreg. Results?). No author or authors of any paper can claim exclusive credit for it; why, otherwise should there always be acknowledgements? Under the new arrangement, individuals will still get the 'carrot' by belonging to a group which publishes a lot of good papers, and they won't miss the 'stick'. Yours faithfully,

$$
\text { T. B. TANG }
$$

Imperial College of Science and Technology,

Department of Metallurgy,

Royal School of Mines,

London SW7 